\title{
Laying the Foundation for the Clean Energy Age
}

\section{Lynne Robinson}

The task before them seemed daunting, at best, when the Energy Materials Blue Ribbon Panel first convened on February 18, 2010. As Diran Apelian, Panel chair, described their charge at the time, "We need to clearly identify the opportunities and solutions for materials science and engineering (MSE) in the energy sector to transform the "way we do it now.",

Since that day two years ago, more than 100 of the brightest minds in MSE and related disciplines have volunteered their knowledge, insights, and untold hours of work to what has become known as the TMS "Linking Transformational Materials and Processing" project. Coordinated by TMS on behalf of the U.S. Department of Energy (DOE) Advanced Manufacturing Office (previously the Industrial Technologies Program), the "project" has come to reflect a grassroots effort engaging an array of professional societies representing more than 75,000 scientists and engineers.

Providing a framework for this study was the Blue Ribbon Panel's Vision Report that prioritized materials and processing-driven breakthroughs with the highest potential impact across energy sources and use. With the Vision Report's publication in June 2010, TMS launched the next phase of the effort by convening four Technical Working Groups to identify the most promising research and development opportunities within the broad technical themes presented in the Vision Report. Their work was published in Opportunity Analysis for Materials Science and Engineering in January 2011 and served as the basis for an in-depth review of specific technologies, carried out by five Innovation Impact Teams that met at TMS headquarters during June 2011.

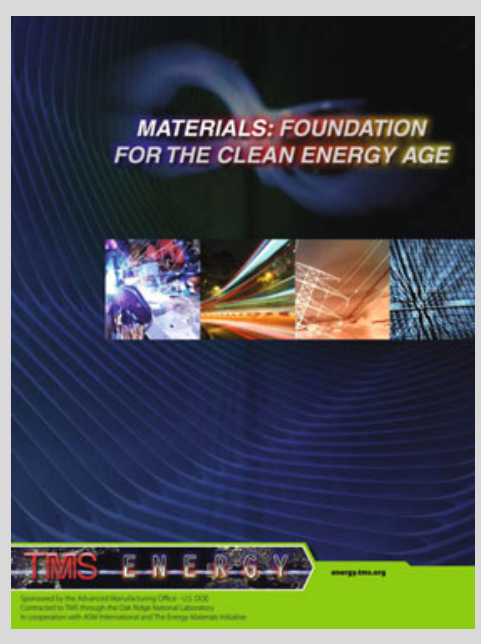

Figure 1. Materials: Foundation for the Clean Energy Age is being distributed to all TMS members as a special insert in this issue of JOM. It is also available for download in the Publications section of the TMS Energy website at energy .tms.org/publications.aspx, as are all of the other reports noted in this article.

The culmination of these deliberations was published in the December 2011 Innovation Impact Report.

The Innovation Impact Report identifies 54 specific opportunities that could save more than 2,800 trillion Btu, avoid 435 million tons of $\mathrm{CO}_{2}$ emissions, and eliminate $\$ 65$ billion in unproductive energy expenditures by U.S. businesses every year. To facilitate sharing this information beyond the MSE community, TMS has published Materials: Foundation for the Clean Energy Age, a booklet summarizing, in non-technical language, the key findings of all three phases of the project within the context of their contributions to a strong and progressive manufacturing economy (Figure 1).

As the "Linking Transformational Materials and Processing" project transitions to this next phase, JOM asked members of the Energy Materials Blue Ribbon panel for their perspectives on the potential impact of this work. Participating in this roundtable discussion were Apelian, Enrique J. Lavernia, distinguished professor and dean, College of Engineering, University of California, Davis; Alan Taub, vice president, Global Research \& Development, General Motors Company; and Jeffrey Wadsworth, president and chief executive officer, Battelle.

JOM: What are the key takeaways from this project and its reports?

WADSWORTH: Well, it is not a new point, but clearly MSE breakthroughs are key enablers for many energy efficiency and carbon reduction strategies. I think this is a compelling issue that leads to several policy imperatives. First, there needs to be sustained investment in MSE research. Second, there needs to be an increased focus on manufacturing process advances. Third, the idea of developing a national energy roadmap has great merit. Finally, a concentrated movement to cultivate a skilled workforce is a very real need.

TAUB: MSE will definitely play a large role in addressing the energy sustainability challenge. But, a corollary takeaway is that industry, government, and academia must work together to provide the materials breakthroughs required to effect large-scale change.

LAVERNIA: Environmental impact has also emerged as a key component in advanced materials manufacturing, providing an opportunity for materials scientists. There are breakthrough opportunities for a plethora of industries that are based on materials technology. Success will depend on our ability to design and implement systems, rather 


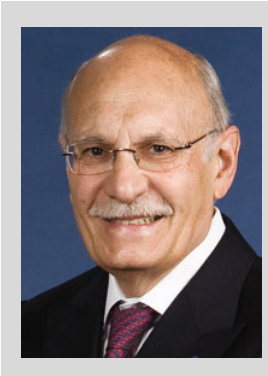

Diran Apelian

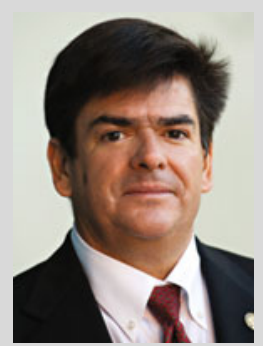

Enrique J. Lavernia

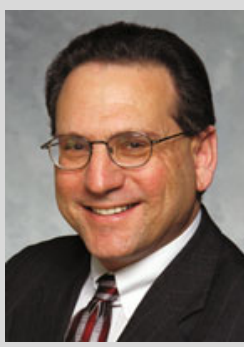

Alan Taub

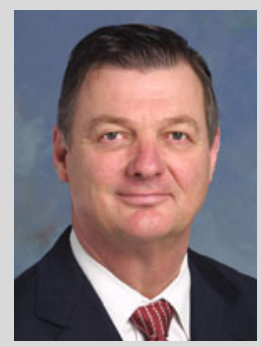

Jeffrey Wadsworth than individual materials, that can capitalize on materials and process acceleration tools.

APELIAN: There are tremendous opportunities ahead that will enable us to sustain development of a renewable energy economy in the 21 st century. The opportunities articulated in the Innovation Impact Report are powerful in that they make the case and the value proposition is clear!

\section{JOM: How was this project unique?}

TAUB: The Innovation Impact Report is important because it is based on input from a broad range of experts spanning a large number of energy applications, including manufacturing, transportation, and energy generation and storage. The result is a comprehensive look at opportunities for materials researchenabled breakthroughs in energy.

LAVERNIA: The use of five Innovation Impact Teams in the final phase of the project, with participation from industry, academia, and national laboratories, provided a unique perspective with both depth and breadth. The resulting report identifies specific materials and engineering breakthrough opportunities in distinct industries, and predicts timelines for implementation.

APELIAN: The process that was followed was extraordinary. This was not a report penned by a committee of 18 to 20 members! It was prepared with much grassroots support and input, framed by a vision that was put together by 21 thought leaders of the MSE community.

JOM: What were some of the project's most surprising developments and outcomes?

WADSWORTH: I don't know if it is a surprise, but the financial savings that are available as a result of materi- als improvements are a reminder about how important this work is.

LAVERNIA: From my perspective, I was surprised by two things. The first one is how many energy-related research opportunities are already available for materials scientists and engineers. And, second, regardless of the distinct characteristics of many of the processes/materials discussed and studied, there is convergence as far as the requirements for a breakthrough.

TAUB: As the project developed, it was interesting to note the common themes that emerged across the application sectors. This clearly shows that progress toward energy diversification and increased product efficiency depends on breakthroughs that need to be driven by the MSE community.

APELIAN: I saw this process more as a confirmation of the fact that "when you get a bunch of knowledgeable folks together and when they all look at the same data, they will invariably come to the same set of conclusions.'

JOM: What do you feel are the greatest challenges to implementing these recommendations?

LAVERNIA: The MSE community needs to start thinking in terms of systems, rather than individual materials - we need to inject environmental impact into all materials problems.

WADSWORTH: Making change is hard. Working on topics that are needed, versus topics that are comfortable, is actually difficult to do. Manufacturing research is needed as much as science research. Paradoxically, countries that are recent entrants into high technology can leap ahead as they are not burdened by a culture of incremental change or resistance to change.

TAUB: This study surfaced common challenges and opportunities that cross many of the application sectors. Agencies like the DOE and societies like TMS can play a strong role in enhancing communication and identifying synergies among the researchers in these different areas.

JOM: What is your hope for the long-term impact of this effort?

WADSWORTH: Throughout history it has been demonstrated, time and again, that there are winners and losers as we go though changes in how we generate, use, and mitigate the environmental impacts of energy. It is clear, as one studies the Innovation Impact Report, that there are advances within reach in myriad areas of MSE and manufacturing. Those entities that reach solutions first will be the winners. It is not enough just to be innovative; the notion of the rate of innovation needs to become part of the conversation. Most economists agree that about half of our economy has its origin in science and technology, and so this race to invention is imperative.

TAUB: The energy sustainability challenge needs to be one of the key focus areas for the MSE community. Studies like this are important for focusing resources on the highest impact opportunities.

APELIAN: My specific recommendation to the MSE community is to be an advocate for the cause. Our societal needs call MSE to action. Each one of us needs to be a spokesperson for the importance of our field and the need for resources to enable us to make an impact and contribute.

\section{JOM: What has TMS's involvement} brought to this effort?

LAVERNIA: My sense is that this would not have happened without the leadership of TMS. Because of its reputation as an impartial and rigorous organization, TMS is able to catalyze this type of complex, multi-variable study.

TAUB: TMS did an outstanding job of bringing together the key technology thought leaders in this area. The result is a powerful assessment of the opportunities that breakthroughs in materials research can bring to create a sustainable energy future. 